\title{
Chartism and Exchange Rate Volatility
}

\author{
Mikael Bask \\ University of Helsinki, RUESG and HECER
}

Discussion Paper No. 71

June 2005

ISSN 1795-0562

HECER - Helsinki Center of Economic Research, P.O. Box 17 (Arkadiankatu 7), FI-00014 University of Helsinki, FINLAND, Tel +358-9-191-28780, Fax +358-9-191-28781,

E-mail info-hecer@helsinki.fi, Internet www.hecer.fi 


\title{
Chartism and Exchange Rate Volatility
}

\begin{abstract}
The purpose of this paper is to implement theoretically, the observation that the relative importance of fundamental versus technical analysis in the foreign exchange market depends on the time horizon in currency trade. For shorter time horizons, more weight is placed on technical analysis, while more weight is placed on fundamental analysis for longer horizons. The theoretical framework is the Dornbusch (1976) overshooting model, where moving averages is the technical trading technique used by the chartists. The perfect foresight path near long-run equilibrium is derived, and it is shown that the magnitude of exchange rate overshooting is larger than in the Dornbusch (1976) model. Specifically, the extent of overshooting depends inversely on the time horizon in currency trade. How changes in the model's structural parameters endogenously affect this time horizon and the magnitude of exchange rate overshooting along the perfect foresight path are also derived.
\end{abstract}

JEL Classification: F31, F41

Keywords: Excess volatility, foreign exchange, moving averages, overshooting, technical analysis, trading technique.

\author{
Mikael Bask \\ Department of Economics \\ P.O. Box 17 (Arkadiankatu 7) \\ FIN-00014 University of Helsinki \\ FINLAND \\ e-mail: mikael.bask@helsinki.fi
}




\section{Introduction}

The empirical literature demonstrates that there are often large movements in nominal exchange rates that are apparently unexplained by macroeconomic fundamentals. Frankel and Froot (1990, p. 73), for example, write:

"[...] the proportion of exchange rate movements that can be explained even after the fact, using contemporaneous macroeconomic variables, is disturbingly low".

It was Meese and Rogoff (1983) who first demonstrated that it is very difficult to explain systematically, much less predict, movements in nominal exchange rates. They found that at horizons up to one year, none of the foreign exchange models could outperform the predictions of a random walk model. Remarkably, this was true even when the predictions of the models were based on realized, and not predicted, values of the explanatory variables. Thus, the out-of-sample fit of the exchange rate models was extremely poor. Today, researchers have continued to find it difficult to firmly demonstrate systematic relationships between movements in nominal exchange rates and macroeconomic fundamentals. See the discussion in the Economic Journal by Dixon (1999), Flood and Rose (1999), MacDonald (1999) and Rogoff (1999).

In a seminal paper by Dornbusch (1976), it is shown that large movements in nominal exchange rates could be consistent with perfect foresight. Specifically, a theory of exchange rate movements under perfect capital mobility, a slow adjustment of the real sector relative to the monetary sector due to sticky goods prices, and an expectations formation that is consistent with the model is developed in the paper. After a monetary disturbance, the exchange rate responds more strongly than necessary to maintain long-run equilibrium. The reason for this overshooting effect is the stickiness of goods prices since it initially restricts prices from making their required contribution to overall adjustment of the economy to long-run equilibrium.

Dornbusch (1976), however, disregard from the fact that a large proportion of chief foreign exchange dealers also use other tools than macroeconomic analysis in their currency trade. In November 1988, Taylor and Allen (1992) conducted a questionnaire survey for the Bank of England on the foreign exchange market in London. The survey covered 353 banks and financial institutions, with a response rate of over 60 per cent, and was among the first to ask specifically about the use of technical analysis, or chartism, among chief foreign exchange dealers. The results of the survey were striking, with two per cent of the respondents reported never to use fundamental analysis in forming their exchange rate expectations, while 90 per cent reported placing some weight on technical analysis at the intraday to one week horizon. At longer time horizons, however, Taylor and Allen (1992) found that the importance of chartism became less pronounced.

That chartism is extensively used in currency trade has also been confirmed by Menkhoff (1997), who conducted a survey in August 1992 on the German market, by Lui and Mole (1998), who conducted a survey in February 1995 on the Hong Kong market, by Oberlechner (2001), who conducted a survey in 
the spring 1996 on the markets in Frankfurt, London, Vienna and Zurich, and by Cheung and Chinn (2001), who conducted a survey between October 1996 and November 1997 on the U.S. market. A general observation in these surveys is that a skew towards reliance on technical, as opposed to fundamental, analysis at shorter time horizons was found, which became gradually reversed as the length of the horizon considered was increased.

Basically, technical analysis utilizes past exchange rates to detect patterns that are extrapolated into the future. Focusing on past exchange rates is not considered as a shortcoming for currency traders using these techniques since a primary assumption behind chartism is that all relevant information about future exchange rate movements is contained in past movements. Thus, technical analysis is purely behavioristic in nature and does not examine the underlying reasons of market participants nor the decision-making dynamics of their currency trade. For a theoretical description of technical trading techniques used in the foreign exchange market, see Neely (1997).

Frankel and Froot (1986) were the first to utilize a chartist-fundamentalist setup in a foreign exchange model, where the heterogeneous behavior of currency traders was taken into account. In their model, a bubble in the exchange rate takes off and collapses since the portfolio managers learn more slowly about the model than they are changing it by revising the weights given to the chartists' and fundamentalists' exchange rate expectations. The portfolio managers, those who actually buy and sell foreign exchange in the model, form their expectations as a weighted average of the chartists' and fundamentalists' expectations. See Hommes (2005), a chapter in a forthcoming volume in the Handbook of Computational Economics, for an excellent survey of the literature on heterogeneous agent models in economics and finance.

The purpose of this paper is to explore the effects of moving averages as a technical trading technique in the Dornbusch (1976) overshooting model since moving averages is the most commonly used technique among currency traders using chartism (e.g., Taylor and Allen, 1992, and Lui and Mole, 1998). The specific theoretical contribution is found in the way in which portfolio managers weight the expectations of chartists and fundamentalists. This consists of explicitly modelling the observation that the relative importance of fundamental versus technical analysis in the foreign exchange market depends on the time horizon in currency trade. For shorter time horizons, more weight is placed on technical analysis, while more weight is placed on fundamental analysis for longer horizons.

The results turn out to be quite pleasing. The perfect foresight path near long-run equilibrium is derived, and it is shown that the magnitude of exchange rate overshooting is larger than in the Dornbusch (1976) model. It is also shown that the extent of overshooting depends inversely on the time horizon in currency trade. Thus, the introduction of technical analysis help to better explain the excess volatility of nominal exchange rates mentioned in the quote by Frankel and Froot (1990). How changes in the model's structural parameters endogenously affect the time horizon in currency trade and the magnitude of exchange rate overshooting along the perfect foresight path are also derived. 
The remainder of this paper is organized as follows. The benchmark model and the expectations formations are presented in Section 2. The formal analysis of the model is carried out in Section 3, where the focus is on exchange rate dynamics near long-run equilibrium, even if a global saddle-path stability result also is derived therein. Section 4 contains a concluding discussion of the main results in the paper as well as a discussion of some applications of the model.

\section{Theoretical model}

The benchmark model is presented in Section 2.1, and the expectations formations for the portfolio managers, chartists and fundamentalists are formulated and discussed in Section 2.2.

\subsection{Benchmark model}

The formal structure of the model is presented below. All variables, except the interest rates, are in natural logarithms and Greek letters denote positive structural parameters. The model consists of a real sector and a monetary sector, where the goods market is the real sector, and the money and the international asset markets are the monetary sector.

(1)-(2) below constitute the goods market, where (1) is a Phillips curve relationship without inflation rate expectations and (2) describes the determinants of aggregate demand for domestic goods. The Phillips curve relationship is

$$
\frac{d p}{d t}=\alpha\left(y^{d}-y\right)
$$

where $\frac{d p}{d t}, y^{d}$ and $y$ denote the domestic inflation rate, aggregate demand for domestic goods and aggregate supply of domestic goods, respectively. Goods prices are assumed to be sticky, which means that they respond to market disequilibria, but not fast enough to eliminate the disequilibria instantly. Two extremes are obtained by letting $\alpha \rightarrow \infty$, which is the case of perfectly flexible prices, and by setting $\alpha=0$, which is the case of completely rigid prices. The exclusion of inflation rate expectations in (1) is motivated by the fact that the inflation rate is zero in long-run equilibrium (see Section 3.1 below), and that we investigate the dynamics of the exchange rate near long-run equilibrium.

Aggregate demand for domestic goods is

$$
y^{d}=\beta(s-p)+\gamma y,
$$

where $s$ and $p$ denote the spot exchange rate and the domestic price level, respectively. The exchange rate is defined as the amount of the domestic currency one has to pay for one unit of the foreign currency. Thus, a rising exchange rate means that the domestic currency is losing value. The first term in (2) represents net exports, which depend on the real exchange rate, $s-p$, and the second term represents income-dependent demand for domestic goods. Contrary to the Dornbusch (1976) overshooting model, the dependence of aggregate demand on the domestic interest rate is not considered here. 
(3) constitutes the money market:

$$
m=p+\delta y-\zeta i
$$

where $m$ and $i$ denote the domestic money supply and the domestic interest rate, respectively. Thus, real money demand, $m-p$, depends on aggregate income and the domestic interest rate. The money market is permanently in equilibrium, which is maintained by the assumption of a perfectly flexible domestic interest rate.

(4) constitutes the international asset market:

$$
i=i^{*}+E\left(\frac{d s}{d t}\right)
$$

where $i^{*}$ and $E\left(\frac{d s}{d t}\right)$ denote the foreign interest rate and the expected rate of change of the exchange rate, respectively. This equilibrium condition, also known as uncovered interest rate parity, is based on the assumption that domestic and foreign assets are perfect substitutes, which only can be the case if there is perfect capital mobility. Since the latter is assumed, only the slightest difference in expected yields would draw the entire capital into the asset that offers the highest expected yield. Thus, the international asset market can only be in equilibrium if domestic and foreign assets offer the same expected yield. The equilibrium condition is maintained by the assumption of a perfectly flexible exchange rate.

\subsection{Expectations formations}

According to questionnaire surveys (see cited references in Section 1), the relative importance of fundamental versus technical analysis in the foreign exchange market depends on the time horizon in currency trade. For shorter time horizons, more weight is placed on technical analysis, while more weight is placed on fundamental analysis for longer horizons. In this paper, we formulate this observation as

$$
E\left(\frac{d s}{d t}\right)=E_{c}\left(\frac{d s}{d t}\right) \exp (-\tau)+E_{f}\left(\frac{d s}{d t}\right)(1-\exp (-\tau))
$$

where $E\left(\frac{d s}{d t}\right), E_{c}\left(\frac{d s}{d t}\right)$ and $E_{f}\left(\frac{d s}{d t}\right)$ denote the expected rate of change of the exchange rate according to the portfolio managers, chartists and fundamentalists, respectively. Thus, the portfolio managers' expectations are a weighted average of the chartists' and fundamentalists' expectations, where $\tau$, the time horizon in currency trade, determines the weights.

The most commonly used technique among currency traders using chartism is moving averages (e.g., Taylor and Allen, 1992, and Lui and Mole, 1998). According to this trading technique, buying and selling signals are generated by two moving averages; a short-period moving average and a long-period moving average, where a buy (sell) signal is generated when the short-period moving average rises above (falls below $)^{1}$ the long-period moving average. In its simplest form, the short-period moving average is the current exchange rate and the long-period moving average is an exponential moving average of past exchange rates.

\footnotetext{
1 "Rises above" and "falls below" refer to the intersection of curves in a chart diagram.
} 
Thus, when chartism is used, it is expected that the exchange rate will increase (decrease) when the current exchange rate is above (below) an exponential moving average of past exchange rates:

$$
E_{c}\left(\frac{d s}{d t}\right)=\eta(s-M A)
$$

where $M A$ denotes the moving average. Moreover, this long-period moving average can be written as

$$
M A(t)=\int_{-\infty}^{t} \omega(\mu) s(\mu) d \mu
$$

where the weights given to current and past exchange rates "sum up" to 1 :

$$
\int_{-\infty}^{t} \omega(\mu) d \mu=\int_{-\infty}^{t} \exp (\mu-t) d \mu=1 .
$$

Finally, when fundamental analysis is used, it is expected that the exchange rate will adjust to its fundamental value according to a regressive adjustment scheme:

$$
E_{f}\left(\frac{d s}{d t}\right)=\theta(\bar{s}-s)
$$

where $\bar{s}$ denotes the spot exchange rate in long-run equilibrium, which is the exchange rate's fundamental value. Further, fundamental analysis is based on a model that consists of macroeconomic fundamentals only, which in the present paper is the Dornbusch (1976) overshooting model (see the benchmark model in Section 2.1).

It may be argued that the fundamentalists' expectations formation in (9) is not in the spirit of the Dornbusch (1976) model since the fundamentalists are able to figure out the long-run equilibrium exchange rate but not the path of the exchange rate to this equilibrium. Having the empirical literature on exchange rates in mind, however, it is much easier to accept that movements in the long-run exchange rate is easier to grasp than movements in the spot exchange rate.

\section{Formal analysis of the model}

Since the long-period moving average in (7)-(8) is a function of all past exchange rates, the complete model is not easy to analyze. This is still true even if (7)-(8) can be re-written as the current exchange rate plus an infinite series of time derivatives of increasing orders of the current exchange rate (see Proposition 4 in Section 3.5 below). However, by assuming that the economy has, for a long time, been in long-run equilibrium before a monetary disturbance occurs, the moving average in (7)-(8) is approximately equal to the long-run equilibrium exchange rate (see (10) below). This assumption makes the complete model much more tractable to analyze as is done in Sections 3.1-3.4. A saddle-path stability result is, however, derived in Section 3.5 when (7)-(8) hold. 


\subsection{Long-run equilibrium}

If we assume that the economy has, for a long time, been in long-run equilibrium, the long-period moving average in (7)-(8) is approximately equal to the long-run equilibrium exchange rate:

$$
M A(t) \approx \int_{-\infty}^{t} \omega(\mu) \bar{s} d \mu=\bar{s} \int_{-\infty}^{t} \omega(\mu) d \mu=\bar{s}
$$

Substitution of (10) into the expectations of chartists, i.e., (6), gives

$$
E_{c}\left(\frac{d s}{d t}\right) \approx \eta(s-\bar{s})
$$

i.e., chartists expect an increase (a decrease) in the exchange rate when the current exchange rate is above (below) the long-run equilibrium exchange rate. Thus, chartists expect that the exchange rate will diverge from long-run equilibrium, which means that technical analysis is a destabilizing force in the foreign exchange market.

Substitution of the expectations of fundamentalists and chartists, i.e., (9) and (11) (assuming equality in the equation), into the portfolio managers' expectations in (5) then yield

$$
E\left(\frac{d s}{d t}\right)=\eta(s-\bar{s}) \exp (-\tau)+\theta(\bar{s}-s)(1-\exp (-\tau)) .
$$

Thus, the portfolio managers expect a constant exchange rate in long-run equilibrium since $E\left(\frac{d s}{d t}\right)=0$ when $s=\bar{s}$, which also means, according to the asset market equilibrium condition in (4), that domestic and foreign interest rates are equal in long-run equilibrium. Of course, the fundamentalists and chartists also expect a constant exchange rate in long-run equilibrium since $E_{f}\left(\frac{d s}{d t}\right)=E_{c}\left(\frac{d s}{d t}\right)=0$ when $s=\bar{s}$ (see (9) and (11)).

The equations that describe the money and the international asset markets, i.e., (3)-(4), can be solved to yield the price level in long-run equilibrium, i.e., $\bar{p}$, if the aforementioned equality of the interest rates in long-run equilibrium is utilized:

$$
\bar{p}=m-\delta y+\zeta i^{*} .
$$

Thus, the quantity theory of money holds in the long-run since $\frac{d \bar{p}}{d m}=1$. Furthermore, if we evaluate the equations that describe the goods market, i.e., (1)-(2), in long-run equilibrium and note that the price level is constant, the long-run equilibrium exchange rate is

$$
\bar{s}=\bar{p}+\frac{1-\gamma}{\beta} y .
$$

Thus, purchasing power parity holds in the long-run since $\frac{d \bar{s}}{d \bar{p}}=1$.

\subsection{Stability condition and adjustment to long-run equilibrium}

To derive the stability condition for the model near long-run equilibrium, we start by combining the equations that describe the money and the international asset markets, i.e., (3)-(4), with the portfolio 
managers' expectations in (12) and the long-run equilibrium price level in (13):

$$
s=\bar{s}+\frac{p-\bar{p}}{\zeta(\eta+\theta) \exp (-\tau)-\zeta \theta} .
$$

Thereafter, we re-write the equations that describe the goods market, i.e., (1)-(2), by utilizing the longrun equilibrium exchange rate in (14) and the relationship between the exchange rate and the price level in (15):

$$
\frac{d p}{d t}=\underbrace{\left(\frac{\alpha \beta}{\zeta(\eta+\theta) \exp (-\tau)-\zeta \theta}-\alpha \beta\right)}_{\equiv r_{0}(\tau)}(p-\bar{p}) .
$$

The price adjustment equation in (16) can be solved for the price level to yield

$$
p(t)=\bar{p}+(p(0)-\bar{p}) \exp \left(r_{0}(\tau) t\right) .
$$

Thus, after a change in money supply, the price level begins to adjust to the new long-run equilibrium at rate $r_{0}(\tau)$. Then, substitution of (17) into $(15)^{2}$ gives the time path of the exchange rate after the monetary disturbance:

$$
s(t)=\bar{s}+(s(0)-\bar{s}) \exp \left(r_{0}(\tau) t\right) .
$$

Of course, the exchange rate adjusts to the new long-run equilibrium at the same rate as the price level does.

The model is stable if both the exchange rate and the price level, after a monetary disturbance, do converge to long-run equilibrium. Thus, the stability condition is

$$
r_{0}(\tau)<0,
$$

or, if solving for the time horizon in currency trade,

$$
\left\{\begin{array}{l}
\tau>\log \left(1+\frac{\eta}{\theta}\right) \\
\tau<\log \frac{\zeta \eta+\zeta \theta}{1+\zeta \theta}
\end{array} .\right.
$$

The second inequality in (20) is only relevant when $\zeta \eta>1$ since the time horizon must be non-negative. However, as will clear in the next section, this inequality will be ruled out when the portfolio managers' exchange rate expectations are characterized by perfect foresight.

\subsection{Perfect foresight}

It is important that the portfolio managers' expectations are not arbitrary, and, given the model, do not involve (persistent) prediction errors. Clearly, for the portfolio managers to correctly predict the path of the exchange rate, it must be true that

$$
E\left(\frac{d s}{d t}\right)=\frac{d s}{d t},
$$

\footnotetext{
${ }^{2}$ Note that since (15) holds at any point in time, it also holds at time $t=0$.
} 
which means that the portfolio managers' expectations in (12) can be re-written as

$$
\frac{d s}{d t}=\underbrace{((\eta+\theta) \exp (-\tau)-\theta)}_{\equiv r_{1}(\tau)}(s-\bar{s}) .
$$

Thus, a necessary condition for the exchange rate to converge to long-run equilibrium along the perfect foresight path is

$$
r_{1}(\tau)<0,
$$

or, if solving for the time horizon in currency trade,

$$
\tau>\log \left(1+\frac{\eta}{\theta}\right)
$$

which is a re-statement of the first inequality in (20). Thus, (24) is at the same time the stability condition for the model as well as a necessary condition for the portfolio managers to have perfect foresight.

The time horizon that corresponds to perfect foresight, i.e., $\tau_{p f}$, is given by the solution to

$$
\frac{\alpha \beta}{\zeta(\eta+\theta) \exp \left(-\tau_{p f}\right)-\zeta \theta}-\alpha \beta=(\eta+\theta) \exp \left(-\tau_{p f}\right)-\theta,
$$

where the left-hand and right-hand sides of (25) are the convergence rates of the exchange rate to long-run equilibrium according to (16) and (22), respectively. The general solution of (25) for the perfect foresight time horizon in currency trade is

$$
\tau_{p f}=f(\alpha, \beta, \zeta, \eta, \theta) .
$$

Thus, the perfect foresight time horizon is a function of (most of) the structural parameters in the model and, therefore, endogenously determined within the model.

Proposition 1 The perfect foresight time horizon depends on the structural parameters in the model in the following way:

$$
\left\{\begin{array}{rlrlrl}
\frac{d \tau_{p f}}{d \alpha}>0, & \frac{d \tau_{p f}}{d \beta}>0, & & \frac{d \tau_{p f}}{d \gamma}=0, & & \frac{d \tau_{p f}}{d \delta}=0, \\
\frac{d \tau_{p f}}{d \zeta}<0, & \frac{d \tau_{p f}}{d \eta}>0, & \frac{d \tau_{p f}}{d \theta}<0 . &
\end{array}\right.
$$

Proof. See the Appendix for a proof.

According to Proposition 1, the perfect foresight time horizon is longer, the faster goods prices respond to market disequilibria $(\alpha)$, the stronger the demand for goods responds to changes in the real exchange rate $(\beta)$, and the larger the expected adjustment speed of the exchange rate is according to the chartists $(\eta)$. Thus, in these cases, the portfolio managers place relatively more weight on fundamental analysis when forecasting exchange rate movements.

The opposite is true when the demand for money responds stronger to changes in the interest rate $(\zeta)$, and the larger the expected adjustment speed of the exchange rate is according to the fundamentalists $(\theta)$. In these cases, the portfolio managers place relatively more weight on technical analysis when forecasting exchange rate movements. Finally, the perfect foresight time horizon is not affected by changes in the response of goods demand and money demand to changes in income $(\gamma$ and $\delta)$. 


\subsection{Exchange rate overshooting}

Substitution of the price level and the exchange rate in long-run equilibrium, i.e., (13)-(14), into the relationship between the exchange rate and the price level in (15), and differentiating the resulting equation with respect to the exchange rate and money supply, keeping all other variables constant, give

$$
\left.\frac{d s}{d m}\right|_{\text {long-run equilibrium }}=1+\underbrace{\frac{1}{\zeta \theta-\zeta(\eta+\theta) \exp \left(-\tau_{p f}\right)}}_{\equiv o\left(\tau_{p f}\right)}, \quad \tau_{p f}>\log \left(1+\frac{\eta}{\theta}\right) .
$$

The price level is held constant when deriving (28) since it is assumed to be sticky. Thus, (28) describes the short-run impact on the exchange rate near long-run equilibrium, given perfect foresight, of a change in money supply.

By letting $\tau \rightarrow \infty$, the portfolio managers' expectations coincide with the fundamentalists' expectations. Therefore, the equation describing exchange rate overshooting in Dornbusch (1976) is obtained:

$$
\left.\frac{d s}{d m}\right|_{\text {Dornbusch (1976) }}=1+\frac{1}{\zeta \theta}>1 .
$$

In this case, the magnitude of exchange rate overshooting depends negatively on the interest rate response of money demand $(\zeta)$ as well as the expected adjustment speed of the exchange rate according to the fundamentalists $(\theta)$.

According to the stability condition, i.e., the first inequality in (20) or (24), the time horizon in currency trade must be greater than $\log \left(1+\frac{\eta}{\theta}\right)$. This implies that the extent of exchange rate overshooting is even larger in this model than in the Dornbusch (1976) model:

$$
\left.\frac{d s}{d m}\right|_{\substack{l o n g-\text { run equilibrium, } \\ \tau_{p f} \in\left(\log \left(1+\frac{\eta}{\theta}\right), \infty\right)}} \geq\left.\frac{d s}{d m}\right|_{\text {Dornbusch (1976) }} .
$$

Moreover, the magnitude of overshooting depends inversely on the time horizon in currency trade:

$$
\left.\frac{d s}{d m}\right|_{\text {long-run equilibrium, }} ^{\tau_{p f}=\tau_{0}}>\left.\frac{d s}{d m}\right|_{\substack{\text { long-run equilibrium, } \\ \tau_{p f}=\tau_{1}}}, \quad \tau_{1}>\tau_{0}>\log \left(1+\frac{\eta}{\theta}\right) .
$$

The extent of overshooting depends inversely on the time horizon since for shorter horizons, more weight is placed on technical analysis, which is a destabilizing force in the foreign exchange market. Technical analysis is a destabilizing force since chartists expect that the exchange rate will diverge from long-run equilibrium (see (11)).

In the short-run, before goods prices have time to react, the exchange rate will change more than money supply and, thus, more than is necessary to bring the exchange rate to long-run equilibrium. Sticky goods prices also means that the quantity theory of money does not hold in the short-run since the price level is not affected by a monetary disturbance. Moreover, purchasing power parity does not either hold in the short-run since the exchange rate is affected by a monetary disturbance while the price level is not. However, after a monetary disturbance and the initial overshooting of the exchange rate, the price level and the exchange rate begin to adjust to the new long-run equilibrium according to (17)-(18). 
Proposition 2 The magnitude of exchange rate overshooting, given perfect foresight, depends on the structural parameters in the model in the following way:

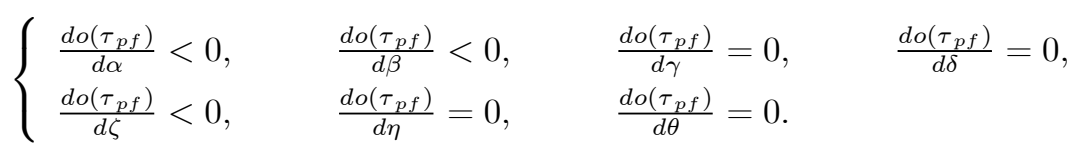

Proof. See the Appendix for a proof.

Proposition 3 The adjustment speed of the exchange rate to long-run equilibrium, given perfect foresight, depends on the structural parameters in the model in the following way:

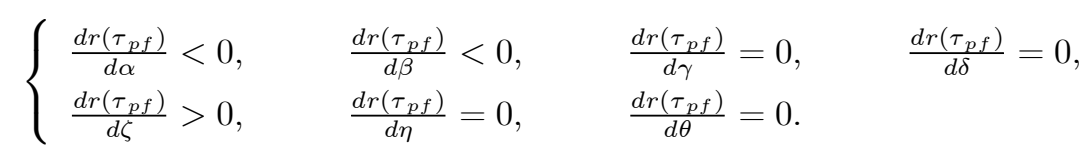

Proof. See the Appendix for a proof.

According to Propositions 2 and 3, the expected adjustment speeds of the exchange rate according to chartism and fundamental analysis $(\eta$ and $\theta)$ do not affect the magnitude of exchange rate overshooting nor the adjustment speed of the exchange rate to long-run equilibrium. If, for example, the fundamentalists believe that the adjustment speed $(\theta)$ will increase, the perfect foresight time horizon will, according to Proposition 1, be shorter. As a consequence, the extent of exchange rate overshooting will, according to (31), increase. This is the indirect effect of an increased expected adjustment speed. However, the direct effect of an increased expected adjustment speed according to the fundamentalists is that the magnitude of overshooting will decrease:

$$
\frac{d o(\tau=\text { constant })}{d \theta}=-\frac{\zeta(1-\exp (-\tau))}{(\zeta \theta-\zeta(\eta+\theta) \exp (-\tau))^{2}}<0 .
$$

Hence, there are two effects that cancel out; a direct effect and an indirect effect via a change in the perfect foresight time horizon. A similar argument applies to a changed expected adjustment speed of the exchange rate according to the chartists $(\eta)$.

There is also a direct effect and an indirect effect of a change in the interest rate response of money demand $(\zeta)$. The indirect effect of a stronger interest rate response is that the perfect foresight time horizon will, according to Proposition 1, be shorter. As a consequence, the extent of exchange rate overshooting will, according to (31), increase. Turning to the direct effect, however, the magnitude of overshooting will decrease:

$$
\frac{d o(\tau=\text { constant })}{d \zeta}=-\frac{\overbrace{\theta-(\eta+\theta) \exp (-\tau)}^{=-r_{1}(\tau)>0}}{(\zeta \theta-\zeta(\eta+\theta) \exp (-\tau))^{2}}<0 .
$$

Taken all in all, a stronger interest rate response of money demand will, according to Proposition 2, decrease the extent of overshooting. However, the adjustment speed of the exchange rate towards longrun equilibrium will, according to Proposition 3, increase.

Furthermore, the magnitude of exchange rate overshooting as well as the adjustment speed of the exchange rate to long-run equilibrium will decrease, the faster goods prices respond to market disequilibria 
$(\alpha)$, and the stronger the demand for goods responds to changes in the real exchange rate $(\beta)$. Since the extent of overshooting does not directly depend on these parameters, the effects are only indirect via a change in the perfect foresight time horizon. Finally, the magnitude of overshooting and the adjustment speed are not affected by changes in the response of goods demand and money demand to changes in income $(\gamma$ and $\delta)$.

\subsection{Saddle-path stability}

In general, we cannot assume that the long-period moving average is equal to the long-run exchange rate as is done in (10). Instead, the moving average in (7)-(8) is a function of all past exchange rates. Unfortunately, this makes the complete model much more intractable to analyze than when it is assumed that the economy is near long-run equilibrium. However, according to Proposition 4 below, (7)-(8) can be re-written as the current exchange rate plus an infinite series of time derivatives of increasing orders of the current exchange rate. The advantage of this is that the derivation of the saddle-path stability result in Proposition 5 below is simplified.

Proposition 4 The long-period moving average in (7)-(8) can be re-written as

$$
M A(t)=s(t)+\sum_{i=1}^{\infty}(-1)^{i} \frac{d^{i} s(t)}{d t^{i}}
$$

Proof. See the Appendix for a proof.

Then, substitution of (36) into (6) yields

$$
E_{c}\left(\frac{d s}{d t}\right)=-\eta \sum_{i=1}^{\infty}(-1)^{i} \frac{d^{i} s}{d t^{i}}
$$

which can be approximated by

$$
E_{c}\left(\frac{d s}{d t}\right) \approx \eta \frac{d s}{d t}-\eta \frac{d^{2} s}{d t^{2}}+\eta \frac{d^{3} s}{d t^{3}}
$$

The approximation in (38) is utilized when deriving the saddle-path stability result since (37) still makes the complete model intractable to analyze.

Proposition 5 When the expectations of chartists is described by (38), the complete model is characterized by saddle-path stability.

Proof. See the Appendix for a proof.

According to (37), but also (38), the expectations of chartists do involve persistent prediction errors since $E_{c}\left(\frac{d s}{d t}\right) \neq \frac{d s}{d t}$. This is not surprising since they do not use an economic model to predict exchange rate movements. Instead, the chartists utilize past exchange rates to detect patterns that are extrapolated into the future. 


\section{Discussion}

Exchange rates are excessively volatile, i.e., movements in nominal exchange rates are larger than movements in macroeconomic fundamentals. Moreover, a very high proportion of chief foreign exchange dealers view fundamental and technical analysis as complementary forms of analysis. Specifically, it has been found in questionnaire surveys that the relative importance of fundamental versus technical analysis depends on the time horizon in currency trade. For shorter time horizons, more weight is placed on technical analysis, while more weight is placed on fundamental analysis for longer horizons.

The point of departure in this paper was to implement the aforementioned observation theoretically into the Dornbusch (1976) overshooting model. The results turned out to be quite pleasing. The perfect foresight path near long-run equilibrium was derived, and it was shown that the magnitude of exchange rate overshooting is larger than in the Dornbusch (1976) model. Moreover, the relative importance of fundamental versus technical analysis implied that the extent of overshooting depends inversely on the time horizon, where the latter is endogenously determined within the model. Thus, the introduction of chartists helped to better explain the excess volatility of nominal exchange rates mentioned in the quote by Frankel and Froot (1990).

The model in the paper may be related to the discussion within monetary economics whether the money demand function is stable or not, i.e., if the parameters in the demand function are constant over the time or if they change. Specifically, the magnitude of exchange rate overshooting, according to Proposition 2, is smaller when the demand for money responds stronger to changes in the interest rate $(\zeta)$, i.e., when the interest rate semi-elasticity of money demand $(-\zeta)$ is larger in absolute value. Thus, even if the volatility of money supply due to shocks is unchanged, the model predicts a less volatile exchange rate during periods of time when the interest rate semi-elasticity of money demand $(-\zeta)$ is larger in absolute value.

Ball (2001), who investigates the long-run money demand in the U.S., asserts that the interest rate semi-elasticity of money demand $(-\zeta)$ was, in absolute value, smaller in the post-war period than what it was in the pre-war period. Thus, in the context of the model in this paper, the exchange rate should be more volatile in the post-war period than what it was in the pre-war period. It is, however, a matter of empirical research to further investigate the relationship between exchange rate volatility and the interest rate semi-elasticity of money demand during the pre- and post-war periods.

The model developed in the paper may also shed some light on the fact that, as a first approximation, countries with flexible exchange rates have more volatile exchange rates than countries with target zones, but equally volatile fundamentals (Flood and Rose, 1999). In fact, the volatility of macroeconomic fundamentals such as money and output do not change much across currency regimes (Flood and Rose, 1995). Therefore, Flood and Rose (1995, p. 5) suggest that macroeconomic fundamentals alone are unable to explain exchange rate volatility: ${ }^{3}$

\footnotetext{
3 "Exchange rate volatility" and "exchange rate stability" are used synonymously by Flood and Rose (1995).
} 
"Intuitively, if exchange rate stability varies across regimes without corresponding variation in macroeconomic volatility, then macroeconomic variables will be unable to explain much exchange rate volatility".

However, by making a clear distinction between the volatility of the exchange rate and the stability of the dynamic system generating the exchange rate, one may resolve the apparent paradox that nominal exchange rates have become more volatile while macroeconomic fundamentals have not. Specifically, a volatile exchange rate may also be the manifestation of a less stable dynamic system, and not only of volatile fundamentals. Thus, having target zones and flexible exchange rates in mind, it may be the case that a target zone for the exchange rate is a more stable dynamic system than flexible exchange rates. It is a matter of theoretical research to further investigate this relationship.

\section{References}

Ball, L. (2001). Another Look at the Long-Run Money Demand. Journal of Monetary Economics, 47, $31-44$.

Cheung, Y.-W. and Chinn, M. D. (2001). Currency Traders and Exchange Rate Dynamics: A Survey of the US Market. Journal of International Money and Finance, 20, 439-471.

Dixon, H. (1999). Controversy: Exchange Rates and Fundamentals. Economic Journal, 109, F652-F654.

Dornbusch, R. (1976). Expectations and Exchange Rate Dynamics. Journal of Political Economy, 84, $1161-1176$.

Flood, R. P. and Rose, A. K. (1995). Fixing Exchange Rates: A Virtual Quest for Fundamentals. Journal of Monetary Economics, 36, 3-37.

Flood, R. P. and Rose, A. K. (1999). Understanding Exchange Rate Volatility Without the Contrivance of Macroeconomics. Economic Journal, 109, F660-F672.

Frankel, J. A. and Froot, K. A. (1986). Understanding the US Dollar in the Eighties: The Expectations of Chartists and Fundamentalists. Economic Record, S62, 24-38.

Frankel, J. A. and Froot, K. A. (1990). Chartists, Fundamentalists and the Demand for Dollars. In Private Behaviour and Government Policy in Interdependent Economies by Courakis, A. S. and Taylor, M. P., eds., Oxford University Press, 73-126.

Hommes, C. H. (2005). Heterogeneous Agent Models in Economics and Finance. In Handbook of Computational Economics, Volume 2: Agent-Based Computational Economics by Judd, K. L. and Tesfatsion, L., eds., Elsevier Science. Forthcoming.

Lui, Y.-H. and Mole, D. (1998). The Use of Fundamental and Technical Analyses by Foreign Exchange Dealers: Hong Kong Evidence. Journal of International Money and Finance, 17, 535-545.

MacDonald, R. (1999). Exchange Rate Behaviour: Are Fundamentals Important? Economic Journal, 109, F673-F691. 
Meese, R. and Rogoff, K. (1983). Empirical Exchange Rate Models of the Seventies: Do They Fit Out of Sample? Journal of International Economics, 14, 3-24.

Menkhoff, L. (1997). Examining the Use of Technical Currency Analysis. International Journal of Finance and Economics, 2, 307-318.

Neely, C. J. (1997). Technical Analysis in the Foreign Exchange Market: A Layman's Guide. Federal Reserve Bank of St. Louis Review, 79 (5), 23-38.

Oberlechner, T. (2001). Importance of Technical and Fundamental Analysis in the European Foreign Exchange Market. International Journal of Finance and Economics, 6, 81-93.

Rogoff, K. (1999). Monetary Models of Dollar/Yen/Euro Nominal Exchange Rates: Dead or Undead? Economic Journal, 109, F655-F659.

Taylor, M. P. and Allen, H. (1992). The Use of Technical Analysis in the Foreign Exchange Market. Journal of International Money and Finance, 11, 304-314.

\section{Appendix}

Proof of Proposition 1 Let

$$
x_{0}(\tau) \equiv(\eta+\theta) \exp (-\tau)-\theta
$$

Then, according to (25), the perfect foresight time horizon satisfies

$$
\frac{\alpha \beta}{\zeta x_{0}\left(\tau_{p f}\right)}-\alpha \beta=x_{0}\left(\tau_{p f}\right),
$$

which has the solution

$$
x_{0}\left(\tau_{p f}\right)=-\frac{\alpha \beta}{2} \pm \sqrt{\frac{\alpha^{2} \beta^{2}}{4}+\frac{\alpha \beta}{\zeta}} .
$$

However, since the perfect foresight time horizon has to satisfy $\tau_{p f}>\log \left(1+\frac{\eta}{\theta}\right)$, which implies that $x_{0}\left(\tau_{p f}\right)<0$, it follows that

$$
x_{0}\left(\tau_{p f}\right)=-\frac{\alpha \beta}{2}-\sqrt{\frac{\alpha^{2} \beta^{2}}{4}+\frac{\alpha \beta}{\zeta}} .
$$

The perfect foresight time horizon can be solved for by combining (A.1) and (A.4):

$$
\tau_{p f}=-\log \left(\frac{\theta}{\eta+\theta}-\frac{\alpha \beta}{2(\eta+\theta)}-\sqrt{\frac{\alpha^{2} \beta^{2}}{4(\eta+\theta)^{2}}+\frac{\alpha \beta}{\zeta(\eta+\theta)^{2}}}\right)=\log \underbrace{\frac{2 \sqrt{\zeta}(\eta+\theta)}{\sqrt{\zeta}(2 \theta-\alpha \beta)-\sqrt{4+\alpha \beta \zeta} \sqrt{\alpha \beta}}}_{\equiv x_{1}},
$$

where $x_{1}>1$ since $\tau_{p f}>0$. Then,

$$
\begin{aligned}
\frac{d \tau_{p f}}{d \alpha} & =\frac{d \tau_{p f}}{d x_{0}\left(\tau_{p f}\right)} \frac{d x_{0}\left(\tau_{p f}\right)}{d \alpha}=\left(\frac{d x_{0}\left(\tau_{p f}\right)}{d \tau_{p f}}\right)^{-1} \frac{d x_{0}\left(\tau_{p f}\right)}{d \alpha} \\
& =\underbrace{\left(-(\eta+\theta) \exp \left(-\tau_{p f}\right)\right)^{-1}}_{<0} \cdot \underbrace{\left(-\frac{\beta}{2}-\frac{\frac{2 \alpha \beta^{2}}{4}+\frac{\beta}{\zeta}}{2 \sqrt{\frac{\alpha^{2} \beta^{2}}{4}+\frac{\alpha \beta}{\zeta}}}\right)}_{<0}>0,
\end{aligned}
$$




$$
\begin{aligned}
\frac{d \tau_{p f}}{d \beta} & =\frac{d \tau_{p f}}{d x_{0}\left(\tau_{p f}\right)} \frac{d x_{0}\left(\tau_{p f}\right)}{d \beta}=\left(\frac{d x_{0}\left(\tau_{p f}\right)}{d \tau_{p f}}\right)^{-1} \frac{d x_{0}\left(\tau_{p f}\right)}{d \beta} \\
& =\underbrace{\left(-(\eta+\theta) \exp \left(-\tau_{p f}\right)\right)^{-1}}_{<0} \cdot \underbrace{\left(-\frac{\alpha}{2}-\frac{\frac{2 \alpha^{2} \beta}{4}+\frac{\alpha}{\zeta}}{2 \sqrt{\frac{\alpha^{2} \beta^{2}}{4}+\frac{\alpha \beta}{\zeta}}}\right)}_{<0}>0,
\end{aligned}
$$

and

$$
\begin{aligned}
\frac{d \tau_{p f}}{d \zeta} & =\frac{d \tau_{p f}}{d x_{0}\left(\tau_{p f}\right)} \frac{d x_{0}\left(\tau_{p f}\right)}{d \zeta}=\left(\frac{d x_{0}\left(\tau_{p f}\right)}{d \tau_{p f}}\right)^{-1} \frac{d x_{0}\left(\tau_{p f}\right)}{d \zeta} \\
& =\underbrace{\left(-(\eta+\theta) \exp \left(-\tau_{p f}\right)\right)^{-1}}_{<0} \cdot \underbrace{\left(-\frac{-\frac{\alpha \beta}{\zeta^{2}}}{2 \sqrt{\frac{\alpha^{2} \beta^{2}}{4}+\frac{\alpha \beta}{\zeta}}}\right)}_{>0}<0 .
\end{aligned}
$$

The expression for the perfect foresight time horizon in (A.5) has the derivatives

$$
\begin{gathered}
\frac{d \tau_{p f}}{d \gamma}=0, \\
\frac{d \tau_{p f}}{d \delta}=0, \\
\frac{d \tau_{p f}}{d \eta}=\frac{1}{x_{1}} \frac{d x_{1}}{d \eta}=\frac{1}{x_{1}} \frac{2 \sqrt{\zeta}}{\sqrt{\zeta}(2 \theta-\alpha \beta)-\sqrt{4+\alpha \beta \zeta} \sqrt{\alpha \beta}}=\frac{1}{x_{1}} \frac{x_{1}}{\eta+\theta}=\frac{1}{\eta+\theta}>0,
\end{gathered}
$$

and

$$
\begin{aligned}
\frac{d \tau_{p f}}{d \theta} & =\frac{1}{x_{1}} \frac{d x_{1}}{d \theta}=\frac{1}{x_{1}} \frac{2 \sqrt{\zeta}(\sqrt{\zeta}(2 \theta-\alpha \beta)-\sqrt{4+\alpha \beta \zeta} \sqrt{\alpha \beta})-2 \sqrt{\zeta}(\eta+\theta) \cdot 2 \sqrt{\zeta}}{(\sqrt{\zeta}(2 \theta-\alpha \beta)-\sqrt{4+\alpha \beta \zeta} \sqrt{\alpha \beta})^{2}} \\
& =\frac{1}{x_{1}}\left(\frac{x_{1}}{\eta+\theta}-x_{1} \frac{x_{1}}{\eta+\theta}\right)=\frac{1-x_{1}}{\eta+\theta}<0,
\end{aligned}
$$

and the proof is completed.

Proof of Proposition 2 According to (28) and (A.1)-(A.2),

$$
o\left(\tau_{p f}\right) \equiv \frac{1}{\zeta \theta-\zeta(\eta+\theta) \exp \left(-\tau_{p f}\right)}=-\frac{1}{\zeta x_{0}\left(\tau_{p f}\right)}=-1-\frac{x_{0}\left(\tau_{p f}\right)}{\alpha \beta},
$$

which has the derivatives

$$
\begin{aligned}
& \frac{d o\left(\tau_{p f}\right)}{d \alpha}=\underbrace{\frac{1}{\left(\zeta x_{0}\left(\tau_{p f}\right)\right)^{2}}}_{>0} \cdot \underbrace{\frac{d x_{0}\left(\tau_{p f}\right)}{d \alpha}}_{<0}<0, \\
& \frac{d o\left(\tau_{p f}\right)}{d \beta}=\underbrace{\frac{1}{\left(\zeta x_{0}\left(\tau_{p f}\right)\right)^{2}}}_{>0} \cdot \underbrace{\frac{d x_{0}\left(\tau_{p f}\right)}{d \beta}}_{<0}<0, \\
& \frac{d o\left(\tau_{p f}\right)}{d \gamma}=-\frac{1}{\alpha \beta} \cdot \underbrace{\frac{d x_{0}\left(\tau_{p f}\right)}{d \gamma}}_{=0}=0, \\
& \frac{d o\left(\tau_{p f}\right)}{d \delta}=-\frac{1}{\alpha \beta} \cdot \underbrace{\frac{d x_{0}\left(\tau_{p f}\right)}{d \delta}}_{=0}=0,
\end{aligned}
$$




$$
\begin{aligned}
& \frac{d o\left(\tau_{p f}\right)}{d \zeta}=\underbrace{-\frac{1}{\alpha \beta}}_{<0} \cdot \underbrace{\frac{d x_{0}\left(\tau_{p f}\right)}{d \zeta}}_{>0}<0, \\
& \frac{d o\left(\tau_{p f}\right)}{d \eta}=-\frac{1}{\alpha \beta} \cdot \underbrace{\frac{d x_{0}\left(\tau_{p f}\right)}{d \eta}}_{=0}=0,
\end{aligned}
$$

and

$$
\frac{d o\left(\tau_{p f}\right)}{d \theta}=-\frac{1}{\alpha \beta} \cdot \underbrace{\frac{d x_{0}\left(\tau_{p f}\right)}{d \theta}}_{=0}=0,
$$

where results in the proof of Proposition 1 are utilized in the derivations, and the proof is completed.

Proof of Proposition 3 According to (22) and the fact that $r_{1}\left(\tau_{p f}\right)=r\left(\tau_{p f}\right)$,

$$
r\left(\tau_{p f}\right) \equiv(\eta+\theta) \exp \left(-\tau_{p f}\right)-\theta=x_{0}\left(\tau_{p f}\right),
$$

which has the derivatives

$$
\begin{aligned}
& \frac{d r\left(\tau_{p f}\right)}{d \alpha}=\frac{d x_{0}\left(\tau_{p f}\right)}{d \alpha}<0, \\
& \frac{d r\left(\tau_{p f}\right)}{d \beta}=\frac{d x_{0}\left(\tau_{p f}\right)}{d \beta}<0, \\
& \frac{d r\left(\tau_{p f}\right)}{d \gamma}=\frac{d x_{0}\left(\tau_{p f}\right)}{d \gamma}=0, \\
& \frac{d r\left(\tau_{p f}\right)}{d \delta}=\frac{d x_{0}\left(\tau_{p f}\right)}{d \delta}=0, \\
& \frac{d r\left(\tau_{p f}\right)}{d \zeta}=\frac{d x_{0}\left(\tau_{p f}\right)}{d \zeta}>0, \\
& \frac{d r\left(\tau_{p f}\right)}{d \eta}=\frac{d x_{0}\left(\tau_{p f}\right)}{d \eta}=0,
\end{aligned}
$$

and

$$
\frac{d r\left(\tau_{p f}\right)}{d \theta}=\frac{d x_{0}\left(\tau_{p f}\right)}{d \theta}=0,
$$

where results in the proof of Proposition 1 are utilized in the derivations, and the proof is completed.

Proof of Proposition 4 By using integration by parts repeatedly, (7)-(8) can be re-written as

$$
\begin{aligned}
M A(t) & =s(t)-\int_{-\infty}^{t} \exp (\mu-t) \frac{d s(\mu)}{d \mu} d \mu \\
& =s(t)-\frac{d s(t)}{d t}+\int_{-\infty}^{t} \exp (\mu-t) \frac{d^{2} s(\mu)}{d \mu^{2}} d \mu \\
& =s(t)-\frac{d s(t)}{d t}+\frac{d^{2} s(t)}{d t^{2}}-\int_{-\infty}^{t} \exp (\mu-t) \frac{d^{3} s(\mu)}{d \mu^{3}} d \mu \\
& =\cdots \\
& =s(t)+\sum_{i=1}^{\infty}(-1)^{i} \frac{d^{i} s(t)}{d t^{i}},
\end{aligned}
$$

and the proof is completed. 
Proof of Proposition 5 The dynamic system consisting of (1)-(5) (9) and (38) (assuming equality in the equation) can be re-written as a system of four first-order differential equations via the following steps. Firstly, (1)-(2) and (14) yields

$$
\frac{d p}{d t}=-\alpha \beta(p-\bar{p})+\alpha \beta(s-\bar{s})
$$

Secondly, (3)-(4) and (13) yields

$$
E\left(\frac{d s}{d t}\right)=\frac{p-\bar{p}}{\zeta}
$$

Thirdly, (5), (9) and (38) yields

$$
E\left(\frac{d s}{d t}\right)=\eta\left(\frac{d s}{d t}-\frac{d^{2} s}{d t^{2}}+\frac{d^{3} s}{d t^{3}}\right) \exp (-\tau)+\theta(\bar{s}-s)(1-\exp (-\tau))
$$

Fourthly, combine (A.31)-(A.32) and solve for $\frac{d^{3} s}{d t^{3}}$ :

$$
\frac{d^{3} s}{d t^{3}}=\frac{\exp (\tau)}{\zeta \eta}(p-\bar{p})+\frac{\theta(\exp (\tau)-1)}{\eta}(s-\bar{s})-\frac{d s}{d t}+\frac{d^{2} s}{d t^{2}}
$$

Then, the system of first-order differential equations can be written as

$$
\left\{\begin{array}{l}
\frac{d p}{d t}=-\alpha \beta(p-\bar{p})+\alpha \beta(s-\bar{s}) \\
\frac{d s}{d t} \equiv u \\
\frac{d u}{d t} \equiv v \\
\frac{d v}{d t}=\frac{\exp (\tau)}{\zeta \eta}(p-\bar{p})+\frac{\theta(\exp (\tau)-1)}{\eta}(s-\bar{s})-u+v
\end{array} .\right.
$$

The Jacobian matrix evaluated at equilibrium, i.e., $\frac{d p}{d t}=\frac{d s}{d t}=\frac{d u}{d t}=\frac{d v}{d t}=0$, is then

$$
J=\left(\begin{array}{cccc}
-\alpha \beta & \alpha \beta & 0 & 0 \\
0 & 0 & 1 & 0 \\
0 & 0 & 0 & 1 \\
\frac{\exp (\tau)}{\zeta \eta} & \frac{\theta(\exp (\tau)-1)}{\eta} & -1 & 1
\end{array}\right)
$$

which means that the characteristic equation, $\operatorname{det}(J-\lambda I)=0$, is

$$
\lambda^{4}+(\alpha \beta-1) \lambda^{3}-(\alpha \beta-1) \lambda^{2}+\left(\alpha \beta-\frac{\theta(\exp (\tau)-1)}{\eta}\right) \lambda+\frac{\alpha \beta}{\zeta \eta}(\zeta \theta-\exp (\tau)(1+\zeta \theta))=0
$$

where $I$ is the identity matrix, and $\lambda_{1}, \lambda_{2}, \lambda_{3}$ and $\lambda_{4}$ are the roots to the dynamic system. In order to establish the number of roots with a negative real part, a positive real part and a real part that is zero, 
respectively, the Routh-Hurwitz analysis is used. Therefore, the following array of values is created:

1

$a_{1}$

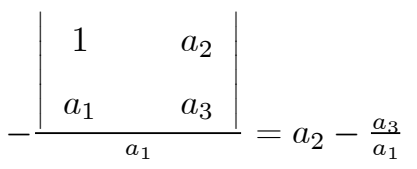

$-\frac{\left|\begin{array}{cc}a_{1} & a_{3} \\ a_{2}-\frac{a_{3}}{a_{1}} & a_{4}\end{array}\right|}{a_{2}-\frac{a_{3}}{a_{1}}}=a_{3}-\frac{a_{1}^{2} a_{4}}{a_{1} a_{2}-a_{3}}$

$-\frac{\left|\begin{array}{cc}a_{2}-\frac{a_{3}}{a_{1}} & a_{4} \\ a_{3}-\frac{a_{1}^{2} a_{4}}{a_{1} a_{2}-a_{3}} & 0\end{array}\right|}{a_{3}-\frac{a_{1}^{2} a_{4}}{a_{1} a_{2}-a_{3}}}=a_{4}$ $a_{2}$

$a_{3}$

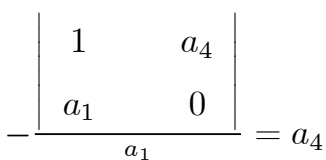

$-\frac{\left|\begin{array}{cc}a_{1} & 0 \\ a_{2}-\frac{a_{3}}{a_{1}} & 0\end{array}\right|}{a_{2}-\frac{a_{3}}{a_{1}}}=0$

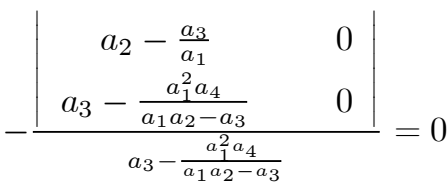

$a_{4}$

0

0

where $a_{1}, a_{2}, a_{3}$ and $a_{4}$ are coefficients in the following polynomial:

$$
\lambda^{4}+a_{1} \lambda^{3}+a_{2} \lambda^{2}+a_{3} \lambda+a_{4}=0
$$

Since there are no row of the array with all zeros, there are no roots with a real part that is zero. Then, to have four roots with a negative real part, the following conditions must hold:

$$
\left\{\begin{array}{l}
a_{1}>0, \quad a_{2}-\frac{a_{3}}{a_{1}}>0 \\
a_{3}-\frac{a_{1}^{2} a_{4}}{a_{1} a_{2}-a_{3}}>0, \quad a_{4}>0
\end{array}\right.
$$

i.e., the number of sign changes in the first column of the array is zero. But $a_{4}>0$ implies that the time horizon must be negative since

$$
\tau<\log \frac{\zeta \theta}{1+\zeta \theta}<0
$$

Thus, (A.36) does not have four roots with a negative real part. Then, to have four roots with a positive real part, the following conditions must hold:

$$
\left\{\begin{array}{l}
a_{1}<0, \quad a_{2}-\frac{a_{3}}{a_{1}}>0 \\
a_{3}-\frac{a_{1}^{2} a_{4}}{a_{1} a_{2}-a_{3}}<0, \quad a_{4}>0
\end{array}\right.
$$

i.e., the number of sign changes in the first column of the array is four. But since $a_{4}>0$ implies that the time horizon must be negative, (A.36) does not have four roots with a positive real part. Thus, at least one root has a negative real part and at least one root has a positive real part, which means that the dynamic system in (A.34) is characterized by saddle-path stability. 